\title{
An Autoantibody in Narcolepsy Disrupts Colonic Migrating Motor Complexes
}

\author{
Michael W. Jackson, Joanne H. Reed, Anthony J. F. Smith, and Tom P. Gordon \\ Autoimmunity Research Laboratory, Department of Immunology, Allergy and Arthritis, Flinders Medical Centre and Flinders University, Adelaide, South \\ Australia 5001, Australia
}

\begin{abstract}
Despite strong circumstantial evidence for the autoimmune hypothesis of narcolepsy, conventional immunological methods have failed to detect an autoantibody. This study investigated the real-time effects of narcoleptic immunoglobulins on a spontaneous colonic migrating motor complex (CMMC) preparation. IgG from patients with narcolepsy with cataplexy or healthy controls was added directly to isolated mouse colons undergoing CMMC activity to test for autoantibodies that disrupt colonic motility. The effect of immunoglobulins prepared for clinical intravenous treatment (IVIg) on autoantibody-mediated colonic disruption was also assessed. Narcoleptic IgGs markedly reduced the frequency of CMMCs or irreversibly abolished them. Abrogation of CMMCs was followed by an increase in the resting tension of the colon preparation and appearance of atropine-sensitive phasic smooth muscle contractions. IVIg partially neutralized the inhibitory effect of narcoleptic IgG on the CMMCs. The dramatic effect of narcoleptic IgG on CMMC generation is consistent with an autoantibody-mediated disruption of enteric neural pathways. The ex vivo whole-organ approach allows real-time examination of the physiological effects of the narcoleptic autoantibody and offers a new avenue for exploring the autoimmune basis of narcolepsy. The neutralizing effect of IVIg on the autoantibody provides a rationale for the reported clinical improvement in cataplexy when IVIg are given at disease onset.
\end{abstract}

Key words: autoimmunity; neuron; neuromuscular; autonomic; antibody; myenteric

\section{Introduction}

Human narcolepsy is a serious acquired disorder causing excessive daytime sleepiness and abnormal manifestations of rapid eye movement sleep such as cataplexy (Overeem et al., 2001; Scammell, 2003). Human narcolepsy with cataplexy is characterized by deficiencies in hypocretin (orexin) neurotransmission, most likely due to a loss of hypocretin producing neurons in the hypothalamus (Peyron et al., 2000; Thannickal et al., 2000; Blouin et al., 2005; Crocker et al., 2005). There is considerable circumstantial evidence that narcolepsy is autoimmune-mediated (for review, see Black, 2005). Most compelling is the remarkable association of narcolepsy with the HLA-DQB1 0602 allele (Rogers et al., 1997; Mignot et al., 2001), while clues from anti-Ma2 paraneoplastic encephalitis suggest that an autoimmune process can result in narcolepsy with cataplexy (Overeem et al., 2004). However, intensive efforts to identify a specific antigenic target of either a B-cell or T-cell response in narcolepsy have been unsuccessful (for review, see Scammell, 2006; Overeem et al., 2008). Although the dominant view is that narcolepsy is caused by deficiencies in hypothalamic hyporexin (hypocretin) neurotransmis-

Received Sept. 18, 2008; revised 0ct. 20, 2008; accepted 0ct. 22, 2008.

This work was supported by Project Grant 375106 from the National Health and Medical Research Council of Australia. We thank Dr. Doug McEvoy for assistance in recruiting the patients, Dr. Nicholas Spencer for advice on the CMMC assay, and Dr. Pamela McCombe for critical comments on this manuscript.

Correspondence should be addressed to Dr. Michael W. Jackson, Department of Immunology, Allergy and Arthritis, Flinders University, GPO Box 2100, Adelaide, South Australia 5001, Australia. E-mail: michael.jackson@flinders.edu.au. D0I:10.1523/JNEUROSCI.4489-08.2008

Copyright $\odot 2008$ Society for Neuroscience $\quad 0270-6474 / 08 / 2813303-07 \$ 15.00 / 0$ sion, recent studies have failed to detect autoantibodies against orexin or orexin receptors (Black et al., 2005b,c; Tanaka et al., 2006). Another study reported reactivity of CSF IgG with rat hypothalamic extract but a specific antigen has not been identified (Black et al., 2005a). A recent extensive immunohistochemical screening for autoantibodies against human lateral hypothalamic neurons from paraffin-embedded tissue was negative apart from one patient whose sera bound to nerve endings projecting on to orexin-producing neurons (Overeem et al., 2006).

Given the lack of success in identifying an autoantibody in patients with narcolepsy by routine immunological techniques, we have developed an alternative approach that utilizes physiological assays sensitive to autoantibodies that bind to a receptor or ion channel and modify its function by activating or inhibiting the target. Such antibodies are typically present in extremely low serum concentrations and react preferentially with native epitopes present in live tissue. Accordingly, they will not be detected by methods such as indirect immunofluorescence and immunoblotting that involve denaturation of target antigens. These are known as functional autoantibodies and have been reported in a range of autoantibody-mediated neurological disorders and other autoimmune diseases (for review, see Waterman et al., 2006). In an earlier study, passive transfer of narcoleptic IgG to mice produced cholinergic hyperactivity in isolated smooth muscle strips (Smith et al., 2004). However, the passive transfer assay has not yielded consistent results, potentially related to the loss of a responder substrain or priming factor (Smith et al., 2007), both of which can influence the outcome of whole animal IgG passive 
transfer (Ji et al., 2001; Fischetti et al., 2005; Reynolds et al., 2006). This method is also limited by fixed-point readouts that cannot distinguish primary from secondary effects of antibody and variability in the bioavailability of the injected IgG. The aim of this study was to develop an alternative physiological approach that would allow direct addition of patient IgG and real-time recording of autoantibody-mediated effects on neural pathways.

In this study, we have used a spontaneous, isolated whole colon migrating motor complex (CMMC) preparation to investigate the functional activity of IgGs from patients with narcolepsy with cataplexy. This organ bath technique has been used recently to discover a functional autoantibody in type 1 diabetes that activates smooth muscle L-type calcium channels, and has an advantage over isolated smooth muscle strip assays in being able to detect autoantibodies whose binding depends upon different activation and inactivation states of ion channels or receptors (Jackson et al., 2004). IgG from patients with narcolepsy with cataplexy profoundly inhibits CMMCs and induces spontaneous, phasic cholinergic contractions in the colonic smooth muscle. Furthermore, the functional activity of narcoleptic IgG was neutralized by immunoglobulins prepared for clinical intravenous treatment (IVIg). The ex vivo CMMC assay, in which narcoleptic IgG can be added directly to the preparation after baseline recordings, offers an improved method over whole animal passive transfer for investigating the properties of the putative functional autoantibody.

\section{Materials and Methods}

Preparation of IgG and antibody fragments. Total IgG was purified from blood collected from six patients with narcolepsy (4 women; mean age 48.3 years, range $19-81$; mean duration of illness 28.0 years, range $4-39$ ) from the Adelaide Institute for Sleep Health, Repatriation General Hospital, South Australia and six healthy controls ( 4 women; mean age 44.5 years, range 22-65). Patients with narcolepsy met the revised International Classification of Sleep Disorders (ICSD2) criteria for the diagnosis of narcolepsy. All were positive for HLA-DR2/DQB1 ${ }^{\star} 0602$; had marked daytime sleepiness and unequivocal cataplexy; and had abnormal REM onset sleep confirmed by Multiple Sleep Latency Testing. The study was approved by the Clinical Ethics Committee of the Flinders Medical Centre.

IgG was prepared using the caprylic acid precipitation technique (Steinbuch and Audran, 1969). To standardize IgG preparations for future studies, the method is described in detail. Five milliliters of human serum was lowered to $\mathrm{pH} 4.8$ by the addition of $1 \mathrm{~m}$ acetic acid. The serum was then stirred vigorously while adding $0.37 \mathrm{ml}$ of caprylic acid dropwise (giving a final ratio of $0.74: 10$ ). The caprylic acid/serum mixture was then stirred for $30 \mathrm{~min}$ at room temperature, and centrifuged at 10,000 $\times$ $g$ for $15 \mathrm{~min}$. Supernatant was recovered and filtered through a Millipore $0.25 \mu \mathrm{m} / \mathrm{M}$ filter and the $\mathrm{pH}$ adjusted to 7.4 with $0.5 \mathrm{~m}$ sodium hydroxide. IgG was also purified from some patient serum using Protein $\mathrm{G}$ column chromatography (Amersham) as described previously (Jackson et al., 2004). Purified IgG was then dialyzed against PBS pH $7.4(2 \times 1 \mathrm{~L})$, concentrated to $40 \mathrm{mg} / \mathrm{ml}$ using a Millipore B15 concentrator, and dialyzed against $1 \mathrm{~L}$ of Krebs solution ([mM/L]: $118 \mathrm{NaCl}, 4.7 \mathrm{KCl}, 1.2$ $\mathrm{KH}_{2} \mathrm{PO}_{4}, 1.5 \mathrm{MgSO}_{4}, 25.0 \mathrm{NaHCO}_{3}, 11.0$ D-glucose, and 2.5 $\left.\mathrm{CaCl}_{2}\right)$. IgG concentrations were determined by nephelometry (ICS II; Beckman). Divalent $\mathrm{F}\left(\mathrm{ab}^{\prime}\right)_{2}$ fragments were produced from IVIg (Intragam P; CSL) as described previously (Cavill et al., 2003). Briefly, IVIg was incubated overnight at $37^{\circ} \mathrm{C}$ with pepsin $\left(5 \mathrm{mg} / 100 \mathrm{mg}\right.$ IgG; Sigma). The $\mathrm{F}\left(\mathrm{ab}^{\prime}\right)_{2}$ fragments were purified by repeated passage through a protein A-Sepharose column to remove undigested IgG and the Fc fragment. The preparations were analyzed for purity by nonreducing sodium dodecyl-PAGE.

Functional assay of spontaneous, colonic migrating motor complexes in the intact colon. CMMCs were studied using minor modifications of previously described methods (Jackson et al., 2004). Ten- to twelveweek-old male BALB/C mice (20-30 g) were housed in separate cages on a $12 \mathrm{~h}$ light/dark cycle for at least $72 \mathrm{~h}$ before harvesting of colons. In some experiments, colons were harvested from 10- to 12-week old male $\mathrm{C} 57 \mathrm{~B} / 6$ or A/J mice. Mice were killed in the first $2 \mathrm{~h}$ of the light cycle and colons excised and suspended in a $100 \mathrm{ml}$ organ bath containing Krebs' solution gassed with $95 \% \mathrm{O}_{2} / 5 \% \mathrm{CO}_{2}, \mathrm{pH} 7.4$ at $37^{\circ} \mathrm{C}$. Any fecal matter was gently flushed from the colon and the mesentery dissected free. The mechanical activity of the circular muscle was recorded by three forcedisplacement transducers (ADInstruments) attached at $2 \mathrm{~cm}$ intervals to the mesenteric border of the colon under an initial tension of $6 \mathrm{mN}$. Transducer output was fed into a Quad bridge amplifier (ADInstruments) and recorded via Chart v4.2 software and a PowerLab/8s data acquisition system (ADInstruments).

Experimental protocol and data analysis. After a 60 min equilibration period, 5 control CMMCs were recorded. For analysis of IgG effects on CMMC activity, patient or control IgG was added to give a final concentration of either 0.2 or $0.4 \mathrm{mg} / \mathrm{ml}$. Preliminary experiments demonstrated a dose-dependant loss of CMMC activity with optimal effects obtained at a final concentration of $0.4 \mathrm{mg} / \mathrm{ml}$ of patient IgG. This concentration was used to screen the patient and control IgGs in all subsequent experiments. After a $30 \mathrm{~min}$ incubation, 5 consecutive CMMCs, where present, were recorded in the continued presence of IgG. The amplitude of contraction at each of the three recording points during CMMC activity and the frequency of CMMCs were calculated using the peak parameters: peak amplitude function of the DataPad on Chart v4.2 software (ADInstruments) and the resulting data from the patient and control IgGs compared by one-way ANOVA (amplitude) and unpaired Student's $t$ test (frequency) using GraphPad Prism (ver 3.0a for Macintosh; GraphPad Software). In some experiments, $1 \mu \mathrm{mol} / \mathrm{L}$ atropine (Sigma), $30 \mathrm{nmol} / \mathrm{L}$ of 1,1-dimethyl-4-diphenylacetoxy piperidinium iodide (4-DAMP; Tocris) or $0.6 \mu \mathrm{mol} / \mathrm{L}$ tetrodotoxin (TTX, Alomone Labs) was added to the colon preparations either in the absence or presence of IgG.

Neutralization of IgG from patients with narcolepsy by IVIg. IgG from patients or controls was incubated with equimolar amounts of IVIg or bovine serum albumin (BSA) (final concentration $0.4 \mathrm{mg} / \mathrm{ml}$ ) for $2 \mathrm{~h}$ at RT (Cavill et al., 2003). The effect of patient IgG, with or without IVIg, was then assessed for the ability to disrupt CMMC propagation in the assay of colonic motility.

Absorption of IgG activity by Sepharose-bound $\mathrm{F}\left(a b^{\prime}\right)_{2}$ from IVIg. IgG from patients or healthy controls was passed over either a cyanogen bromide activated Sepharose $4 \mathrm{~B}$ column (Pharmacia) to which $\mathrm{F}\left(\mathrm{ab}^{\prime}\right)_{2}$ from IVIg had been coupled, or a sham column. The unbound flowthrough fraction was passed over the column 2 times, concentrated by ultrafiltration (Minicon) to the same $\operatorname{IgG}$ concentration as that of the starting IgG fraction and tested for the ability to disrupt CMMC propagation in the assay of colonic motility.

\section{Results}

\section{IgG from patients with narcolepsy disrupts colonic CMMC activity}

We have previously reported that passive transfer of narcoleptic IgG to mice produces cholinergic hyperactivity in isolated detrusor smooth muscle strips (Smith et al., 2004). In the current study, we used an alternative ex vivo physiological assay to detect the functional activity of narcoleptic IgG. The methodology allows real-time recording of the effects of IgG on an ex vivo mouse colon preparation, and thus avoids the influence that host factors can exert on whole animal passive transfer experiments. Since the enteric nervous system underlying CMMC activity shares many of the neurotransmitter systems of the brain (Schemann, 2005), we reasoned that the whole colon preparation could be used as a surrogate assay to detect functional autoantibodies against a common neural target. Spontaneous, regular CMMCs were recorded as contractions migrating from proximal to distal colon at intervals of 3-5 min, separated by periods of quiescence, during which inhibitory motor activity occurs (Fig. $1 A$ ). Following the $30 \mathrm{~min}$ incubation period, $9 \mathrm{IgG}$ preparations from 6 individual 

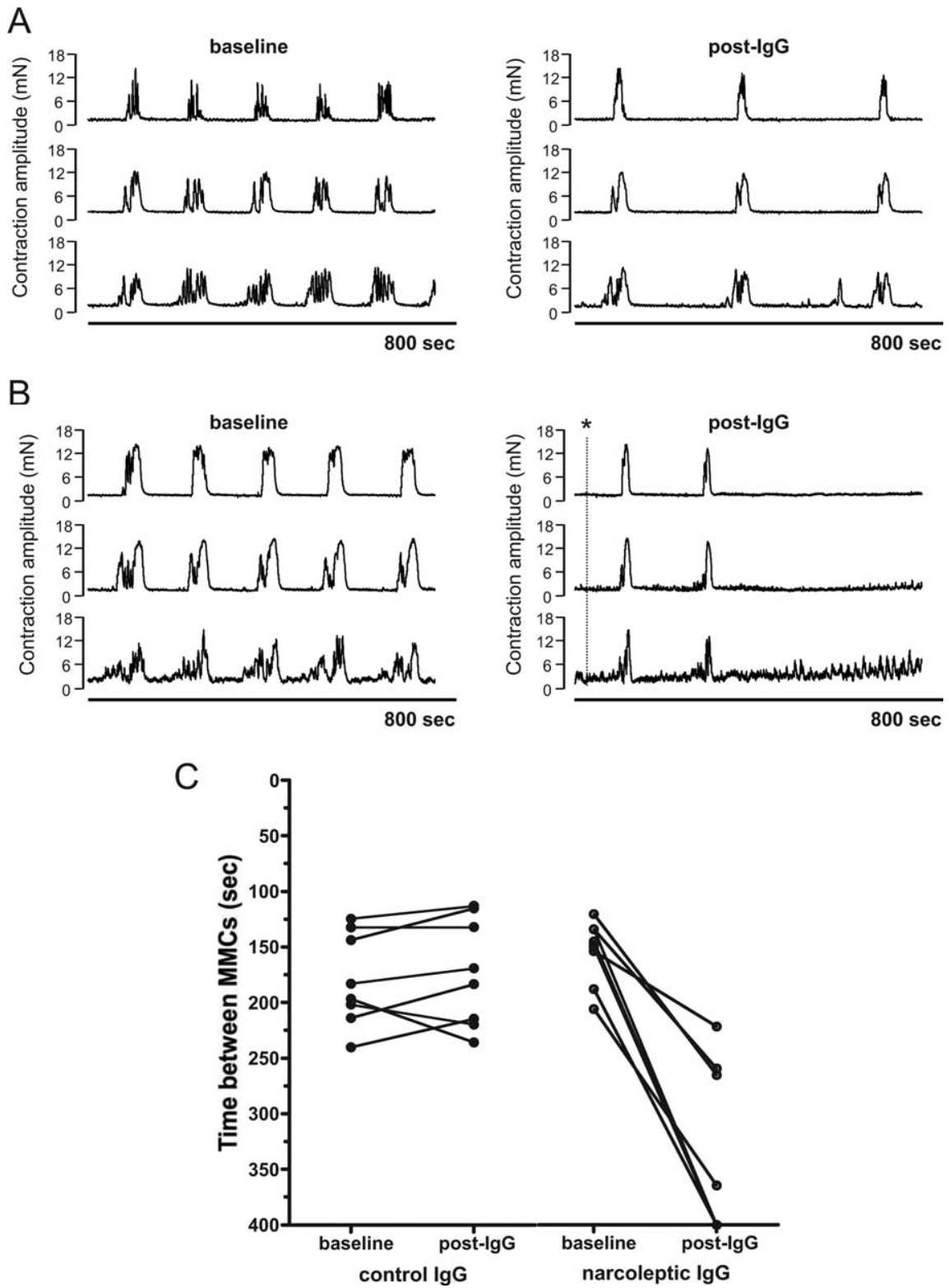

Figure 1. IgG from patients with narcolepsy with cataplexy disrupts CMMC activity recorded in mouse isolated colon. $\boldsymbol{A}$, Representative tracings of patient lgG-induced reduction of CMMC frequency. The normal pattern of CMMC activity (baseline) recorded using 3 force transducers placed along the mesenteric boarder of a colon from proximal to distal. The spontaneous contractile complex occurs every $3-5$ min separated by periods of relative quiescence (resting tone). Following a 30 min incubation, lgG $(0.4 \mathrm{mg} / \mathrm{ml}$ ) from a patient with narcolepsy and cataplexy (post-lgG) markedly reduced CMMC frequency compared with the baseline frequency. The post-lgG trace depicts CMMCs recorded 30 min following the addition of $\lg G$. $\boldsymbol{B}$, Representative tracings of patient IgG-induced loss of CMMC activity. The normal pattern of CMMC activity (baseline) of an individual colon preparation is abolished within $10 \mathrm{~min}$ by addition of $\lg \mathrm{G}^{*}$ ) from a patient with narcolepsy (post-lgG). C, Pooled data of CMMC frequency following the addition of narcoleptic (open circles) or control (closed circles) IgG. Addition to mouse colon of control lgG $(n=8)$ did not alter the frequency of CMMCs ( $p>0.05$, baseline compared with post-lgG by paired $t$ test) (The frequency is represented on the $y$-axis as the time between $C M M(s)$. In contrast, addition of $\lg (n=9)$ from patients with narcolepsy and cataplexy markedly reduced the frequency of CMMCs, or abolished them completely (lines terminating on the $x$-axis) $(p<0.0001$, baseline compared with post-lgG by paired $t$ test).

patients with narcolepsy with cataplexy profoundly disrupted CMMC activity during the recording period by markedly reducing the frequency of the CMMCs $(n=4)$ or abolishing them completely $(n=5)$ (Fig. $1 A-C)$. The first IgG preparations from the three patients tested twice reduced CMMC frequency; IgGs purified from later blood samples from two of these patients abolished CMMCs, whereas IgG from the third patient slowed CMMCs. Compared with baseline CMMC frequency, addition of narcoleptic IgG $(n=4)$ reduced CMMC frequency by a mean of $73.5 \%(p<0.0001$ by paired $t$ test). By comparison, IgGs from healthy controls $(n=9)$ did not significantly reduce CMMC frequencies from baseline recordings $(p>0.05$ by paired $t$ test) (Fig. 1C). Narcoleptic IgG also abolished CMMCs in colons from C57BL/6 and A/J mice (supplemental Fig. $1 A, B$, available at www.jneurosci.org as supplemental material), demonstrating that the narcoleptic IgG effect is conserved across different mouse strains. The apparent lack of dependence on mouse genetic background should facilitate replicative studies. In addition, narcoleptic IgG purified by a Protein G column (in which IgM and IgA were undetectable by nephelometry) mediated the same disruption of CMMCs as IgG purified by caprylic acid precipitation, verifying that the functional activity is being mediated by an IgG autoantibody (supplemental Fig. 1C, available at www. jneurosci.org as supplemental material).

The IgG-induced abrogation of CMMCs appears specific for patients with narcolepsy, since we have not observed this effect with IgGs from an additional 48 patients and controls tested previously on the whole colon preparation (Jackson et al., 2004). Furthermore, IgG from 3 patients with the autoantibody-mediated neurological disorder LEMS did not alter CMMC activity (data not shown). Replacing the Krebs solution in the bath did not restore the CMMC activity.

Narcoleptic IgG-mediated abrogation of CMMCs results in an increase in resting tension and induction of spontaneous, phasic cholinergic activity

In colon preparations where CMMC activity was abolished following incubation with patient $\operatorname{IgG}(n=5)$, an increase in resting muscle tone ranging from 2 to 6 $\mathrm{mN}$ was recorded $\sim 30-60 \mathrm{~min}$ following addition of IgG (Fig. $2 A$ ). Interestingly, in 3 of the 5 preparations this increase in resting tension was associated with the onset of spontaneous, phasic contractions (Fig. $2 B)$. These were abolished by addition of 1 $\mu \mathrm{mol} / \mathrm{L}$ atropine, indicating that they are cholinergic in origin (Fig. $2 B$ ).

TTX, a selective blocker of sodium channels on enteric nerves that has no effect on colonic smooth muscle, has been reported also to abolish CMMCs and increase smooth muscle resting tension (Fida et al., 1997), suggesting that the functional autoantibody in narcolepsy may exert a similar blockade of neuronal activity in the colon preparations. Importantly, narcoleptic IgG did not appear to exert any direct effect on colonic smooth muscle in the current experiments since no change in the amplitude of CMMCs was observed following IgG addition. 
Disruption of colonic CMMC activity by narcoleptic IgG is neutralized in vitro by IVIg

IVIg has proven useful in ameliorating the activity of functional autoantibodies against a number of neuronal targets (Buchwald et al., 2002; Cavill et al., 2003). To evaluate the effect of IVIg on narcoleptic IgG activity in the colon CMMC assay, $20 \mathrm{mg}$ of patient IgG was mixed with an equimolar amount of IVIg or a BSA control. Preincubation of $20 \mathrm{mg}$ of patient IgG with BSA resulted in a significant reduction of CMMC frequency at $60 \mathrm{~min}$ following addition of IgG (47.4\% of baseline frequency, $p=0.0089$ by paired $t$ test) (Fig. 3A). By comparison, addition of the same patient IgG preincubated with IVIg failed to alter the frequency of CMMCs at either 30 or $60 \mathrm{~min}$ postaddition ( $p>0.05$ compared with baseline frequency) (Fig. $3 B, C)$. These findings are consistent with a neutralizing effect of the IVIg on the narcoleptic IgG activity.

The functional activity of narcoleptic IgG is neutralized by antiidiotypic antibodies present in IVIg

IVIg has been proposed to neutralize functional autoantibodies via the presence of antiidiotypic antibodies (Buchwald et al., 2002; Cavill et al., 2003). If IVIg contains antibodies that neutralize the functional autoantibody in narcolepsy IgG, it should be possible to reduce autoantibody activity by passage of patient $\operatorname{IgG}$ over a $\mathrm{F}\left(\mathrm{ab}^{\prime}\right)_{2}$ column derived from IVIg. To test this, two equal fractions of a narcoleptic IgG known to abolish CMMC activity were passed over a $\mathrm{F}\left(\mathrm{ab}^{\prime}\right)_{2}$ IVIg column or a sham column, respectively. Addition of the unbound flow-through fraction of IgG from the sham column $(40 \mathrm{mg})$ abolished CMMCs within $10 \mathrm{~min}$ of addition and was associated with an increase in resting tone and the induction of spontaneous, phasic contractions (Fig. 4A). By comparison, addition of $40 \mathrm{mg}$ of unbound $\mathrm{IgG}$ from the IVIg $\mathrm{F}\left(\mathrm{ab}^{\prime}\right)_{2}$ column to a colon preparation failed to abolish CMMCs and produced only a modest reduction in CMMC frequency of 24.8\% (Fig. 4B). These results are consistent with the presence of an inhibitor of autoantibody activity in the $\mathrm{F}\left(\mathrm{ab}^{\prime}\right)_{2}$ portion of IVIg, presumably an antiidiotypic antibody.

\section{Discussion}

Support for the autoimmune hypothesis of human narcolepsy requires the identification of a specific autoantibody against a defined neural target (Black et al., 2005b; Scammell, 2006; Overeem et al., 2008). Because conventional immunological techniques have failed to identify such an autoantibody, we have pioneered an entirely different approach in which the effects of immunoglobulins from patients with narcolepsy are studied on
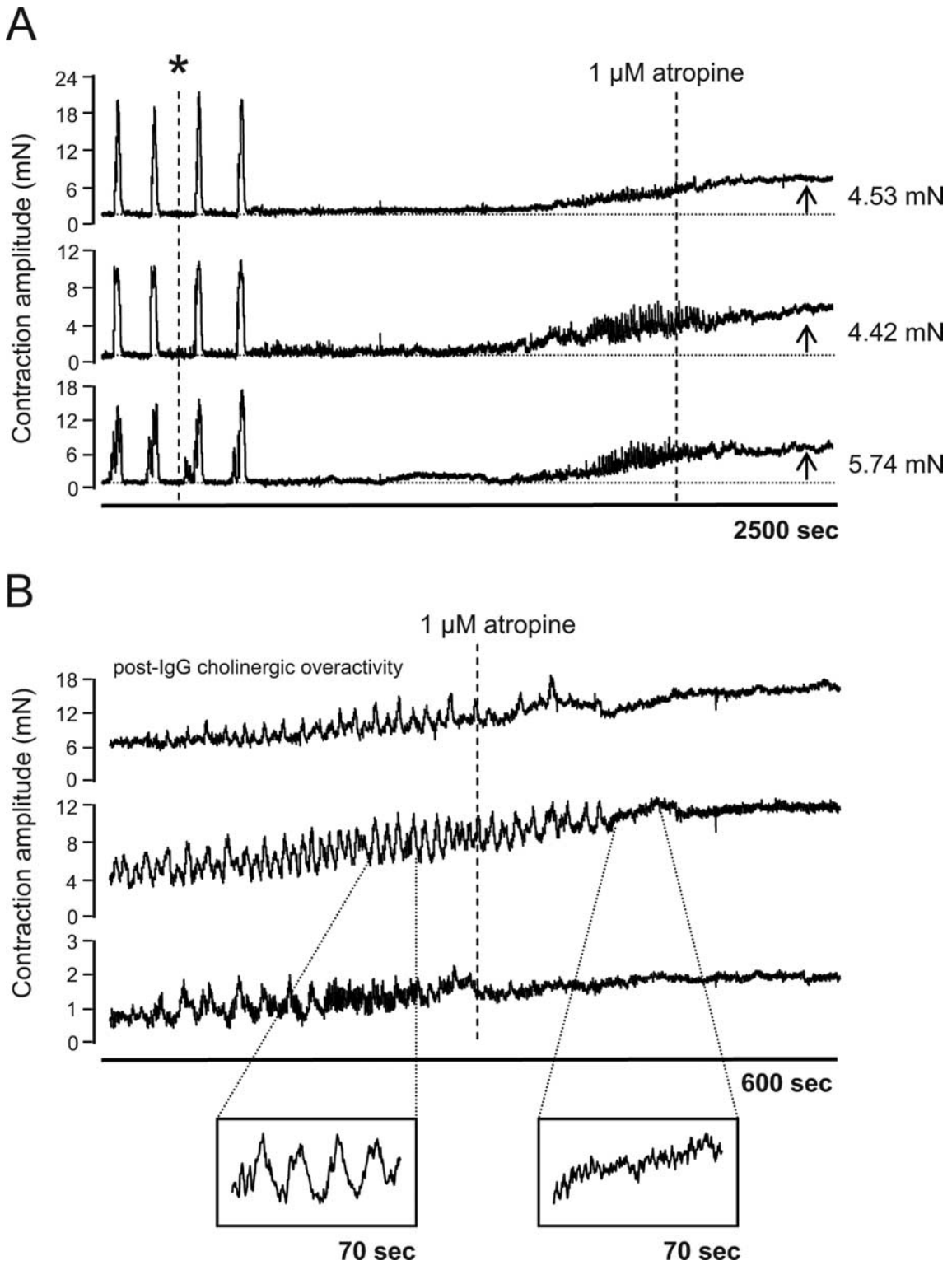

Figure 2. Loss of CMMC activity following addition of narcoleptic $\operatorname{lgg}\left({ }^{*}\right)$ is associated with an increase in resting tone of the smooth muscle and induction of spontaneous, phasic cholinergic contractions. $A$, Representative tracing of CMMC activity in an observed at all 3 colon recording sites. Increased resting tension, ranging from 2 to $6 \mathrm{mN}$ was observed in all preparations where IgG abolished CMMC activity $(n=5)$. B, Representative tracing of spontaneous, phasic contractions in colonic smooth muscle following patient IgG-mediated loss of CMMCs. The contractions were abolished following addition to the preparation of the muscarinic receptor angatonist, atropine, indicating that they are cholinergic in origin.

live tissue. In the current study, we have used a robust ex vivo whole-organ assay to detect a circulating autoantibody in patients with narcolepsy with cataplexy that disrupts neurally mediated CMMCs. The spontaneously active colon can be viewed as a "gut brain" surrogate (Schemann, 2005) in which the physiological effects of the narcoleptic autoantibody can be studied under real-time conditions. As illustrated with IVIg, the CMMC assay can be used to investigate the effects of pharmacological or immune agents on the activity of the autoantibody.

The key finding of this study was that narcoleptic IgG markedly reduced the frequency of CMMCs or irreversibly abolished them. Abrogation of CMMCs was followed by an increase in the resting tension of the colon preparation and the appearance of atropine-sensitive high frequency phasic smooth muscle contrac- 
A
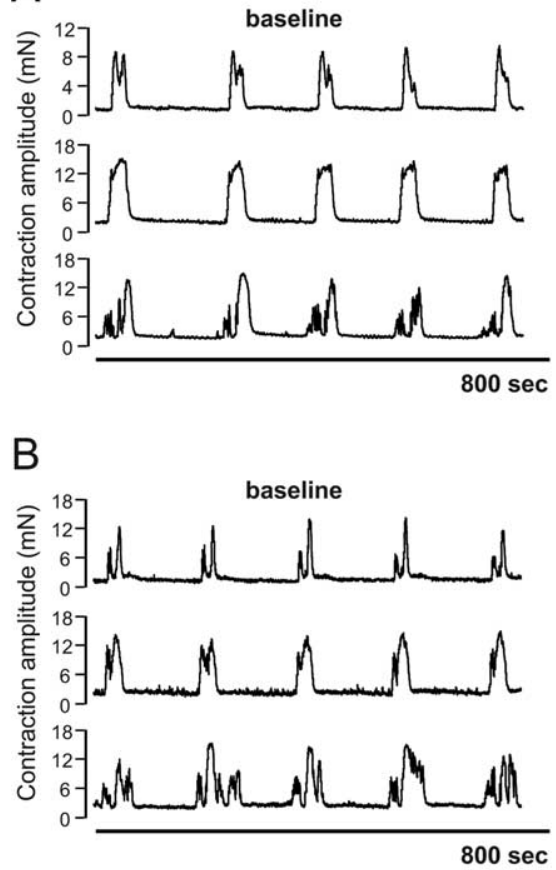
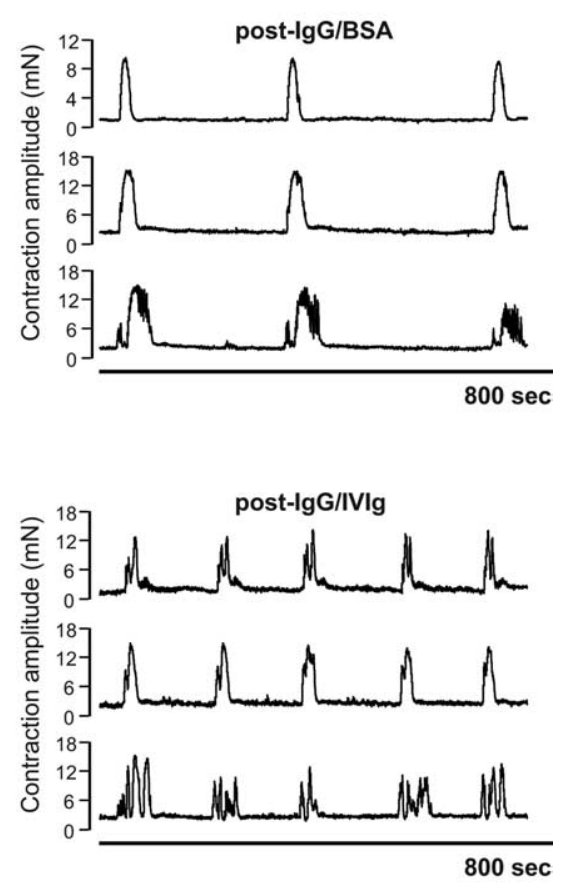

C

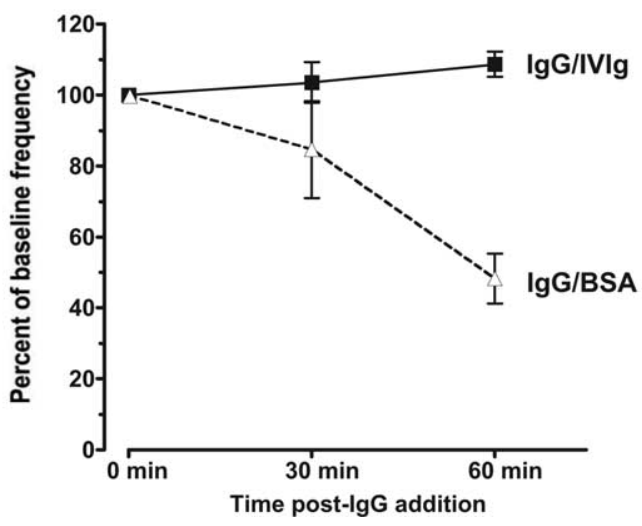

Figure 3. Neutralization of the functional activity of narcoleptic lgG by IVIg. $\boldsymbol{A}$, Addition to an individual colon preparation of narcoleptic $\lg G(20 \mathrm{mg})$ preincubated with an equimolar amount of BSA, markedly reduced CMMC frequency compared with the baseline frequency (post-IgG/BSA). B, Preincubation of narcoleptic $\lg G$ with an equimolar concentration of IVIg (post-lgG/IVIg) prevented the reduction CMMC frequency. $C$, Sets of 5 CMMCs recorded at baseline (0), 30 and 60 min post-lgG. There was no reduction in CMMC frequency for narcoleptic $\mathrm{lgG} / \mathrm{IVIg}>60 \mathrm{~min}$ from baseline, compared with a significant reduction in frequency for $\lg \mathrm{G} / \mathrm{BSA}$ ( $p=0.0089$, CMMC frequency at $60 \mathrm{~min}$ compared with baseline by paired $t$ test). Values are mean and SEM.

We hypothesize that the narcoleptic autoantibody binds to an ion channel or receptor expressed on a population of enteric neurons leading to a disruption of the neural control mechanisms responsible for the generation of CMMCs and tonic inhibition of enteric smooth muscle. Addition of the $\mathrm{F}\left(\mathrm{ab}^{\prime}\right)_{2}$ fragment of narcoleptic IgG also abrogated CMMCs and produced a rise in resting tension and myogenic cholinergic hyperactivity, indicating that the activity is mediated by the antigenic-binding site of the patient antibody (data not shown). We suspect that identification of the neuronal target of the autoantibody will require a combination of pharmacological, immunological and genetic approaches. A potential autoantigen is the nicotinic acetylcholine receptor on cholinergic motor neurons. However, interruption of neural transmission by hexamethonium does not fully mimic the activity of the autoantibody since this drug abolishes CMMCs without increasing the resting tone of the preparation (Fida et al., 1997). A possible effect of the autoantibody on orexin receptors also requires consideration. There is an extensive literature supporting orexin receptors in the gut (Heinonen et al., 2008) and orexin has been reported to prolong cycle length of the migrating myoelectric complex in the rat (Naslund et al., 2002). However, a recent study has questioned the presence of orexin in the murine gut (Baumann et al., 2008) and a large study using a cell-free assay detected autoantibodies to orexin receptors in only a small number of narcolepsy subjects and controls (Tanaka et al., 2006).

IVIg has been reported in a small open trial to reduce the frequency and severity of cataplexy when administered at disease onset, although orexin levels did not change after treatment (Dauvilliers et al., 2004). Since functional autoantibodies in other autoimmune diseases including primary Sjögren's syndrome, type 1 diabetes and Guillian-Barre syndrome are neutral-

tions. Interestingly, the rise in resting muscle tone is mimicked by the sodium channel blocker TTX (Fida et al., 1997) and is consistent with an inhibitory action of the autoantibody on neural pathways that maintain an inhibitory smooth muscle tone, thought to be mediated predominantly by nitrergic mechanisms (Spencer et al., 1998). Loss of this tonic inhibition results in a disinhibited musculature. The narcoleptic IgG-induced cholinergic myogenic hyperactivity appears to be similar to the enhanced cholinergic responses that we reported in isolated smooth muscle strips after passive transfer of IgG (Smith et al., 2004). It is surprising that there are no consistent reports of dysfunction of colon movement in narcolepsy, given the IgG-mediated disruption of CMMCs in vitro. However, bowel symptoms are commonly under-reported and warrant further investigation in patients with narcolepsy. ized by antiidiotypic antibodies present in IVIg (Buchwald et al., 2002; Cavill et al., 2003; Wan et al., 2008), we investigated whether IVIg exerted a protective effect on narcoleptic IgGmediated CMMC dysfunction. Preincubation of IVIg with narcoleptic IgG neutralized the CMMC disruption, and the functional activity of patient IgG was reduced by passage over Sepharose-bound $\mathrm{F}\left(\mathrm{ab}^{\prime}\right)_{2}$ derived from IVIg, findings consistent with the presence of a population of antiidiotypic antibodies in IVIg that neutralize the functional autoantibody. Whether such a mechanism is responsible for the observed clinical improvement reported above remains conjectural, since IVIg has multiple additional mechanisms of action including Fc receptor blockade, interference with complement and cytokines, and modulation of $\mathrm{T}$ and B-cell activation (Kazatchkine and Kaveri, 2001). Although not included in the present study, it will be important to test 
whether IVIg neutralizes the functional activity of IgG samples taken from patients of short disease duration. The role of IVIg in the management of narcolepsy with cataplexy is unresolved and awaits placebo controlled trials.

The goal of identifying a specific pathogenic autoantibody or autoreactive T-cell in human narcolepsy remains a daunting task. The whole-organ physiological approach reported herein offers a new avenue for exploring the hypothesis that narcolepsy is an autoantibody-mediated neurological disorder. An important area for future studies will be to determine the impact of the autoantibody on clinical practice, such as its diagnostic and/or predictive value and relationship to the severity of REM related phenomena. However, the technical complexity of the CMMC assay and the need for large quantities of patient IgG currently limit testing to small numbers of subjects. Identification of the precise antigenic target is likely to lead to the development of a simpler cell-based or immunochemical assay that will prove more suitable for screening large patient cohorts from multiple centers. The CMMC assay will be a useful gold standard for new assay development. The question as to whether the autoantibody is merely a marker of narcolepsy or is involved directly in the pathophysiology of the disorder also remains unresolved, since it is not yet possible to translate findings from the murine CMMC assay to human narcolepsy. Notwithstanding this, the present study is significant because it provides direct evidence for the involvement of humoral autoimmunity in human narcolepsy and has developed a surrogate experimental model for investigating the functional properties of the autoantibody under real-time kinetics.

\section{References}

Baumann CR, Clark EL, Pedersen NP, Hecht JL, Scammell TE (2008) Do enteric neurons make hypocretin? Regul Pept 147:1-3.

Black JL 3rd (2005) Narcolepsy: a review of evidence for autoimmune diathesis. Int Rev Psychiatry 17:461-469.

Black JL 3rd, Avula RK, Walker DL, Silber MH, Krahn LE, Pankratz VS, Fredrickson PA, Slocumb NL (2005a) HLA DQB1*0602 positive narcoleptic subjects with cataplexy have CSF $\lg$ G reactive to rat hypothalamic protein extract. Sleep 28:1191-1192.

Black JL 3rd, Silber MH, Krahn LE, Avula RK, Walker DL, Pankratz VS, Fredrickson PA, Slocumb NL (2005b) Studies of humoral immunity to preprohypocretin in human leukocyte antigen DQB1 ${ }^{*} 0602$-positive narcoleptic subjects with cataplexy. Biol Psychiatry 58:504-509.

Black JL 3rd, Silber MH, Krahn LE, Fredrickson PA, Pankratz VS, Avula R, Walker DL, Slocumb NL (2005c) Analysis of hypocretin (orexin) antibodies in patients with narcolepsy. Sleep 28:427-431.

Blouin AM, Thannickal TC, Worley PF, Baraban JM, Reti IM, Siegel JM (2005) Narp immunostaining of human hypocretin (orexin) neurons: loss in narcolepsy. Neurology 65:1189-1192.

Buchwald B, Ahangari R, Weishaupt A, Toyka KV (2002) Intravenous immunoglobulins neutralize blocking antibodies in Guillain-Barre syndrome. Ann Neurol 51:673-680.

Cavill D, Waterman SA, Gordon TP (2003) Antiidiotypic antibodies neutralize autoantibodies that inhibit cholinergic neurotransmission. Arthritis Rheum 48:3597-3602.
Crocker A, España RA, Papadopoulou M, Saper CB, Faraco J, Sakurai T, Honda M, Mignot E, Scammell TE (2005) Concomitant loss of dynorphin, NARP, and orexin in narcolepsy. Neurology 65:1184-1188.

Dauvilliers Y, Carlander B, Rivier F, Touchon J, Tafti M (2004) Successful management of cataplexy with intravenous immunoglobulins at narcolepsy onset. Ann Neurol 56:905-908.

Fida R, Lyster DJ, Bywater RA, Taylor GS (1997) Colonic migrating motor complexes (CMMCs) in the isolated mouse colon. Neurogastroenterol Motil 9:99-107.

Heinonen M, Purhonen A, Mäkelä K, Herzig K (2008) Functions of orexins in peripheral tissues. Acta Physiol 192:471-485.

Jackson MW, Gordon TP, Waterman SA (2004) Disruption of intestinal motility by a calcium channel-stimulating autoantibody in type 1 diabetes. Gastroenterology 126:819-828.

Ji H, Gauguier D, Ohmura K, Gonzalez A, Duchatelle V, Danoy P, Garchon HJ, Degott C, Lathrop M, Benoist C, Mathis D (2001) Genetic influences on the end-stage effector phase of arthritis. J Exp Med 194:321-330.

Fischetti F, Durigutto P, Pellis V, Debeus A, Macor P, Bulla R, Bossi F, Ziller F, Sblattero D, Meroni P, Tedesco F (2005) Thrombus formation induced by antibodies to beta2-glycoprotein I is complement dependent and requires a priming factor. Blood 106:2340-2346.

Kazatchkine MD, Kaveri SV (2001) Immunomodulation of autoimmune and inflammatory diseases with intravenous immune globulin. N Engl J Med 345:747-755.

Mignot E, Lin L, Rogers W, Honda Y, Qiu X, Lin X, Okun M, Hohjoh H, Miki T, Hsu S, Leffell M, Grumet F, Fernandez-Vina M, Honda M, Risch N (2001) Complex HLA-DR and -DQ interactions confer risk of narcolepsy-cataplexy in three ethnic groups. Am J Hum Genet 68:686-699.

Näslund E, Ehrström M, Ma J, Hellström PM, Kirchgessner AL (2002) Localization and effects of orexin on fasting motility in the rat duodenum. Am J Physiol Gastrointest Liver Physiol 282:G470-479.

Overeem S, Mignot E, van Dijk JG, Lammers GJ (2001) Narcolepsy: clinical features, new pathophysiologic insights, and future perspectives. J Clin Neurophysiol 18:78-105.

Overeem S, Dalmau J, Bataller L, Nishino S, Mignot E, Verschuuren J, Lammers GJ (2004) Hypocretin-1 CSF levels in anti-Ma2 associated encephalitis. Neurology 62:138-140. 
Overeem S, Verschuuren JJ, Fronczek R, Schreurs L, den Hertog H, Hegeman-Kleinn IM, van Duinen SG, Unmehopa UA, Swaab DF, Lammers GJ (2006) Immunohistochemical screening for autoantibodies against lateral hypothalamic neurons in human narcolepsy. J Neuroimmunol 174:187-191.

Overeem S, Black JL 3rd, Lammers GJ (2008) Narcolepsy: immunological aspects. Sleep Med Rev 12:95-107.

Peyron C, Faraco J, Rogers W, Ripley B, Overeem S, Charnay Y, Nevsimalova S, Aldrich M, Reynolds D, Albin R, Li R, Hungs M, Pedrazzoli M, Padigaru M, Kucherlapati M, Fan J, Maki R, Lammers GJ, Bouras C, Kucherlapati R, et al. (2000) A mutation in a case of early onset narcolepsy and a generalized absence of hypocretin peptides in human narcoleptic brains. Nat Med 6:991-997.

Reynolds J, Albouainain A, Duda MA, Evans DJ, Pusey CD (2006) Strain susceptibility to active induction and passive transfer of experimental autoimmune glomerulonephritis in the rat. Nephrol Dial Transplant 21:3398-3408.

Rogers AE, Meehan J, Guilleminault C, Grumet FC, Mignot E (1997) HLA DR15 (DR2) and DQB1 ${ }^{*} 0602$ typing studies in 188 narcoleptic patients with cataplexy. Neurology 48:1550-1556.

Scammell TE (2003) The neurobiology, diagnosis, and treatment of narcolepsy. Ann Neurol 53:154-166.

Scammell TE (2006) The frustrating and mostly fruitless search for an autoimmune cause of narcolepsy. Sleep 29:601-602.

Schemann M (2005) Control of gastrointestinal motility by the "gut brain"- the enteric nervous system. J Pediatr Gastroenterol Nutr 41 Suppl 1:S4-S6.

Smith AJ, Jackson MW, Neufing P, McEvoy RD, Gordon TP (2004) A functional autoantibody in narcolepsy. Lancet 364:2122-2124.

Smith AJ, Jackson MW, Neufing P, Gordon TP (2007) Activity of passively transferred narcolepsy IgG may be influenced by genetic background and immune cofactors. Sleep Biol Rhythms 5:A168.

Spencer NJ, Bywater RA, Taylor GS (1998) Disinhibition during myoelectric complexes in the mouse colon. J Auton Nerv Syst 71:37-47.

Steinbuch M, Audran R (1969) The isolation of IgG from mammalian sera with the aid of caprylic acid. Arch Biochem Biophys 134:279-284.

Tanaka S, Honda Y, Inoue Y, Honda M (2006) Detection of autoantibodies against hypocretin, hcrtrl, and hcrtr2 in narcolepsy: anti-Hcrt system antibody in narcolepsy. Sleep 29:633-638.

Thannickal TC, Moore RY, Nienhuis R, Ramanathan L, Gulyani S, Aldrich M, Cornford M, Siegel JM (2000) Reduced number of hypocretin neurons in human narcolepsy. Neuron 27:469-474.

Wan EC, Gordon TP, Jackson MW (2008) Autoantibodies to calcium channels in type 1 diabetes mediate autonomic dysfunction by different mechanisms in colon and bladder and are neutralized by antiidiotypic antibodies. J Autoimmun 31:66-72.

Waterman SA, Jackson MW, Gordon TP (2006) Functional effects of autoantibodies: the autoimmune diseases, Ed 4 (Rose NR, Mackay IR, eds), pp 217-236. Elsevier, Sydney. 